\title{
Heritability of life span is largely sex limited in Drosophila.
}

\author{
Anne Lehtovaara, Holger Schielzeth, Ilona Flis and Urban Friberg \\ Journal Article
}

\section{Tweet}

N.B.: When citing this work, cite the original article.

Original Publication:

Anne Lehtovaara, Holger Schielzeth, Ilona Flis and Urban Friberg, Heritability of life span is largely sex limited in Drosophila., American Naturalist, 2013. 182(5), pp.653-65.

http://dx.doi.org/10.1086/673296

Copyright: University of Chicago Press

http://www.press.uchicago.edu/

Postprint available at: Linköping University Electronic Press

http://urn.kb.se/resolve?urn=urn:nbn:se:liu:diva-137154

LINKÖPINGS

UNIVERSITET 
Heritability of lifespan is largely sex-limited in Drosophila

\author{
Anne Lehtovaara ${ }^{1,3, \#}$, Holger Schielzeth ${ }^{1,2,4, \#}$, Ilona Flis ${ }^{1,5}$ and Urban Friberg ${ }^{1,6}$ \\ ${ }^{1}$ Ageing Research Group, Dept of Evolutionary Biology, Uppsala University, Norbyvägen 18D, 75236 Uppsala, \\ Sweden \\ ${ }^{2}$ Dept of Evolutionary Biology, Bielefeld University, Morgenbreede 45, 33615 Bielefeld, Germany
}

${ }^{\#}$ These authors contributed equally to this study.

33Anne.Lehtovaara@gmail.com

${ }^{4}$ Holger.Schielzeth@uni-bielefeld.de

${ }^{5}$ I.L.Flis@sussex.ac.uk

6Urban.Friberg@ebc.uu.se

Key words: Additive genetic variation, Aging, Drosophila melanogaster, Heritability,

Lifespan, Sex-specific variation

Figures to be printed in color: Figure 1 and Figure 3

Online enhancement: appendix. Dryad data DOI: doi:10.5061/dryad.q412q

Type of Manuscript: Article 


\begin{abstract}
Males and females differ with respect to lifespan and rate of aging in most animal species. Such sexual dimorphism can be associated with a complex genetic architecture, where only part of the genetic variation is shared between the sexes. To the extent this is true for lifespan and aging is not known, since studies of lifespan have given contradictory results and because aging has not been studied from this perspective. Here we investigate the additive genetic architecture of lifespan and aging in Drosophila melanogaster. We find substantial amounts of additive genetic variation for both traits, and that more than three quarters of this variation is available for sexspecific evolutionary change. This result shows that the sexes have a profoundly different additive genetic basis for these traits, which has several implications. First it translated into an, on average, three times higher heritability of lifespan within compared to between the sexes. Second, it implies that the sexes are relatively free to evolve with respect to these traits. And third, as lifespan and aging are traits that integrate over all genetic factors that contribute to mortal disease, it also implies that the genetics of heritable disease differs vastly between the sexes.
\end{abstract}




\section{Introduction}

Lifespan and aging are important traits both in evolutionary biology and in medicine, as they play a central role in life-history evolution and sum over all genetic variants that contribute to mortal disease (Partridge and Gems 2006). Understanding the quantitative genetics of these traits is therefore essential for both these fields. An interesting aspect of lifespan and aging is that they commonly differ between the sexes in animals (Clutton-Brock and Isvaran 2007; Liker and Szekely 2005; Trivers 1972), as well as in human populations (Hazzard 1986; Maklakov 2008; Teriokhin et al. 2004). Such sex differences may be associated with a complex sexspecific genetic architecture (Poissant et al. 2010). So far only a limited number of studies have looked closer at the genetic architecture of these traits taking both sexes into account (Fox et al. 2004b; Muhlhauser and Blanckenhorn 2004; Zajitschek et al. 2007). Further studies on the inheritance patterns of these traits are hence needed to provide us with a better picture of i) how independently the genetic architecture of traits and trade-offs that determine lifespan and aging can evolve in the sexes and ii) the degree to which mortal diseases in general are heritable between relatives of the same and opposite sex.

The potentially complex genetics of sexually dimorphic traits results from how differences between the sexes evolve. For males and females to acquire different phenotypes through selection the additive intersexual genetic correlation, $r_{\mathrm{MF}}$, has to be less than one (Bonduriansky 2007; Bonduriansky and Chenoweth 2009; Fairbairn et al. 2007; Fairbairn and Roff 2006; Lande 1980; Lande 1987; Reeve and Fairbairn 2001), but see Lynch and Walsh (1998) for a special case. This can be achieved through several different genetic mechanisms (Bonduriansky and Chenoweth 2009), but in all cases involve allelic variants with sex-specific effects.. Traits that show sexual dimorphism hence had an $r_{\mathrm{MF}}$ less than one when the dimorphism evolved, but the degree of sexual dimorphism a trait displays today does not necessarily say anything 
about the current $r_{\mathrm{MF}}$, as selection can fix allelic polymorphisms with sex-specific effects (Meagher 1992; Reeve and Fairbairn 2001). Empirical studies testing for an association between the $r_{\mathrm{MF}}$ and the degree of sexual dimorphism have also given mixed results, where some have shown a negative correlation (Bonduriansky and Rowe 2005; Delph et al. 2010; Delph et al. 2004; McDaniel 2005), whereas other studies have found no association (Ashman and Majetic 2006; Cowley and Atchley 1988; Cowley et al. 1986; association reported in Fairbairn and Roff 2006; Leinonen et al. 2011). A comprehensive meta-analysis of many plant and animal species did however show an overall weak negative association (reviewed in Poissant et al. 2010). The degree to which a trait is sexually dimorphic thus at best seems only weakly related to how much sex-specific variation it hosts.

In Drosophila melanogaster, the quantitative genetics of lifespan has primarily been studied through quantitative trait loci (QTL) analyses. While such analyses are designed to identify major QTLs and not the overall genetic architecture of a trait, they are still informative concerning dominant genetic patterns. Some of these studies have concluded that most QTLs affecting lifespan have sex-specific effects (Curtsinger et al. 1998; Forbes et al. 2004; Leips and Mackay 2002; Nuzhdin et al. 1997; Vieira et al. 2000; Wilson et al. 2006), whereas other studies, in some cases using the exact same lines, have found other or the same QTLs to have largely similar effects in the two sexes (Curtsinger 2002; Nuzhdin et al. 2005; Reiwitch and Nuzhdin 2002; Wang et al. 2004). It is difficult to reconcile these opposing results, but one possibility is that environmental conditions play an important role for the effect genetic variants exert in each sex (Friberg 2005; Reiwitch and Nuzhdin 2002; Wang et al. 2004). Several of the studies that report QTLs with sex-specific effects have maintained flies under rather artificial conditions [virgins kept in isolation (Nuzhdin et al. 1997), very low density of virgin individuals (Leips and Mackay 2002; Vieira et al. 2000), mixed sexes at very low density (Wilson et al. 
2006)], while studies where flies have been kept under conditions more closely matching the environment the flies are adapted to (mixed sex groups at moderate densities) have found QTLs to have similar effect in both sexes (Curtsinger 2002; Nuzhdin et al. 2005; Reiwitch and Nuzhdin 2002; Wang et al. 2004). Another possibility is that many of the identified sex-specific QTLs are artifacts of low power in mapping experiments (Curtsinger 2002; Reiwitch and Nuzhdin 2002), an hypothesis that has at least some empirical support (Forbes et al. 2004). A further complication with several of above studies is that they have been conducted on inbred lines, which makes it difficult to generalize the findings to natural populations, but see (Forbes et al. 2004), and to estimate the amount of standing additive genetic variation.

A low additive intersexual genetic correlation for lifespan and aging would have several implications. First it would allow male and female life-histories to evolve largely independently. Second, it would have an interesting effect on heritability, as additive genetic variation that is not shared between the sexes would cause higher within sex heritabilities (father-to-son and mother-to-daughter) than cross-sex heritabilities (father-to-daughter and mother-to-son). Consequently, opposite-sex relatives would hold less information about an individual's expected lifespan than same-sex relatives. Finally, it would also mean that the type, onset and prevalence of heritable genetic disease, to a degree inversely proportional to the $r_{\mathrm{MF}}$, would be specific to each of the sexes (Ober et al. 2008).

In this study, we investigate the additive genetics of sexual dimorphism in lifespan and aging in D. melanogaster. We were particularly interested in the heritability of these traits within and across the sexes, to understand the potential for sexually independent evolution and how genetic variants that contribute to mortal disease in general are inherited. To accomplish this we employed hemiclonal analysis (Abbott and Morrow 2011; Rice et al. 2005), with which additive 
and phenotypic variation for each sex, and additive genetic covariances between the sexes, can be estimated within a single generation. These estimates were subsequently used to calculate heritabilities within and across the sexes. To minimize the above mentioned problems associated with inbreeding and novel environments, we studied heterozygous individuals in an environment closely resembling the one the flies had been long term adapted to. In addition we also kept flies in single sex groups to test if sexual context influences the degree of sexspecificity of genetic variation, in an attempt to provide a resolution to the contradictory results from previous QTL studies.

In sum we find that the majority of all additive genetic variation is sex-specific for both lifespan and aging, independent of social environment. The prevalence of additive sex-specific variation resulted in a relatively low additive $r_{\mathrm{MF}}$, which caused the heritability of lifespan to be, on average, three times lower between family members of opposite sex compared to those of the

same sex. These results imply that the genetic architecture of traits and trade-offs that determine lifespan and the rate of aging are relatively free to evolve independently in the two sexes, and that the heritability of mortal diseases is in general much higher within compared to across the sexes.

\section{Materials and Methods}

\section{Fly population}

We studied genetic variation in lifespan and aging in Dahomey, a large outbred laboratory population of $D$. melanogaster. This population has been cultured on overlapping generations at $25^{\circ} \mathrm{C}$ on a $12 \mathrm{~h}: 12 \mathrm{~h}$ light-dark cycle, for over 40 years. The fact that this population is outbred, adapted to the laboratory environment, and cultured on overlapping generations makes it ideally suited for studies on genetic variation in lifespan and aging, as the traits can be measured in an 
environment that closely resembles the one the flies have adapted to and because the traits are under selection (as opposed to what they are in many other laboratory populations, where adult flies normally are discarded when only a few days old) (Linnen et al. 2001).

\section{Estimating additive genetic variation through hemiclonal analysis}

We used hemiclonal analysis to study additive genetic variation in lifespan and aging (Abbott and Morrow 2011; Rice et al. 2005). A hemiclone is a set of individuals that all share an identical haploid genome (randomly drawn from the base population), that consists of a copy of each of the three major chromosomes in the D. melanogaster genome (X, AII, AIII, but omits the 4th dot chromosome that comprises $<0.5 \%$ of the genome), while the complementary haploid genome varies randomly between individuals. Since the haploid genome that is shared among all individuals of a hemiclone is tested against many different randomly drawn haploid genomes, the average phenotype of a hemiclone is the breeding value of the haploid genome in focus. Variation among hemiclones can therefore be used to calculate the additive genetic variation. This estimate is devoid of any component of dominance, but may include some epistatic variation (Friberg et al. 2005). From a hemiclone perspective epistatic interactions can be divided into i) those that occur between alleles on the focal haploid genome of the hemiclone, ii) those that occur between alleles on randomly drawn haploid genomes the focal haploid genome is paired up with, and iii) those that occur between the focal and the randomly drawn haploid genomes. Only the first of these three sources of epistatic interactions is included in the breeding value of a hemiclone. Variation among hemiclones is thus is an upper bound of the additive genetic variation, but it should at most include a small component of epistatic variation. Theory and empirical data also suggest that epistatic variation is much smaller compared to the additive genetic variation, in particular for complex traits such as those studies here (Hill et al. 2008). 


\section{Construction of hemiclones}

To create 50 hemicones, we randomly selected 50 males from our base population. These males were individually mated to specially designed clone-generator females (C[1]DX, $y, f / Y$; T[2:3] $b w^{D}$, in, $\left.p^{P}, r d g C, r i, s t / \mathrm{T}[2: 3] b w^{D}, i n, p^{P}, r d g C, r i, s t\right)$. One son was randomly chosen from each of these crosses. The sons were then individually mated to many clone-generator females, to clonally amplify the haploid wild-type genome that each son had inherited from his father. By repeatedly mating males to clone-generator females, each of the different cloned haploid genomes can be maintained indefinitely, as the technique forces the chromosome copies forming the wild-type haploid genome to segregate as one unit. See Rice et al. (2005) for a more detailed description on how hemiclones are constructed and maintained.

\section{Experimental procedures}

After amplifying the hemiclones for 2 generations, we mated 50 males from each hemiclone to 100 virgin Dahomey females (in groups of 10 males and 20 females in each of 5 vials), to produce experimental hemiclone females with the cytogenetic construct replaced with random wild type haploid genomes. To produce hemiclone males with randomly drawn genetic backgrounds we mated 100 males per hemiclone to 150 females (in groups of 10 males and 30 females in each 5 vials) carrying a $\mathrm{Y}$ and an attached-X chromosome (C[1])RM, $y, f)$. The attached-X had been backcrossed into the Dahomey background for 7 consecutive generations just prior the start of the experiments, using 14 vials with 16 Dahomey males and 16 attached$\mathrm{X}$ females. As the Y-chromosome was fully replaced during the backcrossing only $0.78 \%$ of the autosomal background was not replaced by the Dahomey background. Sons from the above crosses inherited a randomly drawn Y-chromosome and autosomes from their mothers and the hemiclone from their fathers. As male and female experimental hemiclones are produced by 
mating male hemiclones (with the cytogenetic construct) to many genetically variable females, no maternal effects contribute to variation between hemiclones within the sexes. However, in the rare event that maternal effects $\times$ offspring genotype interactions exists (male and female hemiclones have genetically distinct mothers) such could potentially contribute to variation between the sexes. The mothers of the experimental males and females were derived from flies that had been reared under controlled density for the previous two generations. We standardized the larval density in all vials to about 150, by adjusting the number of eggs per vial. Vials with female hemiclone eggs were adjusted to 150 eggs, while vials with eggs with male hemoclones were adjusted to 300 , as half of the offspring to $\mathrm{Y}$ attached-X mothers die due to sex chromosome aneuploidy at an early stage.

Male and female hemiclones were assayed for lifespan in two social environments. 100 males and 100 virgin females from each hemiclone were collected over two days. The 100 flies per sex were distributed over two $50 \mathrm{ml}$ shell vials with 50 flies in each. In addition to the focal flies, we added either 50 flies of the same sex (SSE = same-sex environment) or of the opposite sex $(\mathrm{MSE}=$ mixed-sex environment $)$ to each vial. These extra flies were homozygous for the recessive marker ebony $(e)$ which caused them to have a distinctly darker body color compared to the focal wild-type flies. The ebony mutation had previously been backcrossed into the Dahomey genetic background for 4 generations. Adding ebony flies had three purposes: i) to make it possible to measure lifespan and aging in two different social environments (MSE flies had access to partners and could reproduce, while SSE flies could not) ii) to dilute the effect of the focal genotype on the environment the focal genotype was measured in and iii) to be able to keep the density of flies per vial constant, as all ebony flies, and all dead focal flies, were replaced by ebony flies every third week (keeping the total number of flies per vial at 100). We repeated the above procedure four times each two days apart, which resulted in a total of 800 
vials. Flies were flipped every second day to a fresh vial and dead flies were recorded at this point. Vials were flipped until all focal flies had died. In total we scored the lifespan of $\sim 40000$ flies. We note that we produced only a single generation of experimental flies, which allowed us to estimate genetic variances and covariances and to infer within- and cross-sex heritabilities (see below).

\section{Statistical Analysis}

Data was analyzed using mixed effects models fitted by MCMC sampling as implemented in the MCMCglmm package in R 2.12.2 (Hadfield 2010). Individual lifespan was modeled in a random effects model assuming a Gaussian error distribution (see Figure 1 for a distribution of lifespan), where lifespan in each environment and sex was treated as separate response variables and for each of them we estimated a separate trait mean (i.e. separate intercepts). The multiresponse model allowed us to estimate the genetic correlations between environments and sexes directly from the similarity of hemiclone lines in different environments/sexes. Hemiclone and vial identity were fitted as random effects. We allowed an unstructured variance-covariance matrix for the hemiclone effects, which results in 4 estimates for the variances (one for each environment and sex) and 6 covariances between them. The vial and the residual variancecovariance matrix had the off-diagonal elements constrained to zero, since covariances were unidentified in our sampling design: each vial represented only one environment $\times$ sex combination (hence no vial-specific covariances between traits) and each fly experience only one environment (hence no residual covariances). The model in $\mathrm{R}$ syntax was: MCMCglmm(cbind(Fsse, Fmse, Msse, Mmse) $\sim$ trait -1 , random = us(trait):Hemiclone + idh(trait):Vial, rcov = idh(trait):units, family = rep("gaussian", 4)), where Fsse, Fmse, Msse and Mmse are individual lifespans of females in SSE, females in MSE, males in SSE and males in MSE, respectively. 
We used uninformative priors for the random effect and the residual variance-covariance matrices with the diagonal elements equal to the phenotypic variance (specific for each environment $\times$ sex combination) divided by the number of variance components (in this case 3: hemiclone, vial and residual) and a degree-of-believe parameter of 2 . The default priors were used for the fixed effects (intercepts). MCMC chains were run for 110000 iterations with a burn-in of 10000 and a thinning interval of 100. Convergence was checked visually and using the Gelman-Rubin criterion applied to two independent chains.

The software WinModest 1.0.2 (Pletcher 1999) was used to fit Gompertz mortality functions $\mu(t)=\alpha e^{\beta \mathrm{t}}$, where $\mu(t)$ is the mortality rate at age $t, \alpha$ is the initial mortality rate and $\beta$ is the rate of aging, to each vial of 50 flies. In order to estimate the variances and covariances for the aging parameter $\beta$, we fitted a similar model as for lifespan, but omitted the 'vial' random effect, since there was only one estimate of $\beta$ per vial. Priors were chosen equivalent to the lifespan models, chains were run with the same settings and convergence was checked visually and by using the Gelman-Rubin criterion.

From the MCMC chains we extracted the posterior distributions of the additive genetic variances $\left(V_{A}\right)$, narrow-sense heritabilities $\left(h^{2}\right)$, additive-genetic covariances $\left(\operatorname{cov}_{A}\right)$, additive correlations $\left(r_{A}\right)$, sexual dimorphism and some relevant differences between estimates (e.g. between genetic variances in different environments). The hemiclone variances and covariances were multiplied by 2 when calculating the additive genetic variance and covariances, since hemiclones share only $50 \%$ of the genome (Friberg et al. 2005). All these quantities can be estimated from a single generation of experimental flies, where the critical information comes from the similarity of hemiclones (both males and females). 
Above estimates were used to calculate the cross-sex heritability by multiplying the within sex heritability in one sex (that can be thought of as the parental sex) with the genetic correlation $r_{M F}$, i.e. $h_{M F}^{2}=h_{M}^{2} \cdot r_{M F}$ and $h_{F M}^{2}=h_{F}^{2} \cdot r_{M F}$. We also used the above estimates to calculate the proportion of genetic variance in one sex that is free to respond to directional selection when the trait is under stabilizing selection in the other sex (proportion of conditional genetic variance, see Hansen et al. 2003),

$$
P_{A_{M \mid F}}=\left(V_{A_{M}}-\frac{\operatorname{cov}_{A_{M F}}^{2}}{V_{A_{F}}}\right) \cdot V_{A_{M}}{ }^{-1}=1-r_{M F}^{2}=P_{A_{F \mid M}} .
$$

The quantities $h_{M F}^{2}, h_{F M}^{2}, P_{A_{M \mid F}}$ and $P_{A_{F \mid M}}$ can all be calculated from our hemiclone analysis, but also from any other breeding design that allows the estimation of the required variances and covariances. Cross-sex heritabilities estimate how informative the phenotypes from one sex are about breeding values of opposite-sex relatives, just as conventional (within-sex) heritabilities estimate how informative the phenotypes of one sex is about the breeding values of same-sex relatives. In this sense they can be interpreted as mother-to-son and father-to-daughter heritabilities even if they are estimated from a single generation as in our study. Theoretically, cross-sex heritabilities can range between -1 and 1 (depending on the sign of the genetic correlation), but as cross-sex genetic correlations should almost always be positive, the relevant range is between 0 and 1 (as for a conventional heritability). In case of negative genetic correlation one could argue that the degree to which opposite-sex relatives are informative does not depend on whether the effects have the same or opposing effects in the two sexes, so that it is the absolute value of the genetic correlation that matters. Our Bayesian approach allowed us to propagate uncertainty in the estimates of variance and covariances in order to quantify uncertainty in $h_{M F}^{2}, h_{F M}^{2}, P_{A_{M \mid F}}$ and $P_{A_{F \mid M}}$. 
Posterior distributions are summarized by the mean, the standard deviation (equivalent to the standard error) and twice the proportion of samples that was greater/smaller than zero (equivalent to a two-tailed $\mathrm{P}$ value). An exact test of variances against zero and (genetic) correlations against 1 is difficult when using MCMC, because variances are constraint to be $\geq$ 0 and correlations are constraint to be $\leq 1$. We therefore visually inspected the posterior distributions and found them to be approximately normal without marked skew and sufficiently far from the boundaries so that we are confident that they are not affected by boundary problems.

\section{Results}

\section{Sexual dimorphism}

Females lived significantly longer than males in both social environments, but the degree of sexual dimorphism (defined as [sex with higher trait mean]/[sex with lower trait mean] - 1, Lovich and Gibbons 1992) was more pronounced in the SSE compared to the MSE (0.36 vs $0.11, \mathrm{P}<0.001$ ) (Figure 1A,B; Table 1). The Gompertz base line mortality rate parameter $\alpha$ followed a similar pattern and was higher in males than in females (median $\alpha$ : females in SSE $1.40 \times 10^{-6}$, females in MSE $2.54 \times 10^{-6}$, males in SSE $1.10 \times 10^{-4}$, males in MSE $6.00 \times 10^{-5}$; $\mathrm{P}<0.001$ in both environments - test performed on log-transformed $\alpha$ ). The rate of aging parameter $\beta$ did, however, show the opposite pattern, with females aging faster than males in both environments (Figure 1C,D; Table 1) and, if anything, a lower degree of sexual dimorphism in the SSE (0.09 vs $0.11, \mathrm{P}=0.22)$.

\section{Additive genetic variation}


We found significant levels of additive genetic variation in lifespan as well as in the aging parameter $\beta$ for both sexes in both environments (Figure 1A,B; Table 1). The additive genetic variation for lifespan was larger for females in the SSE compared to females in the MSE $(\mathrm{P}=$ 0.004), but there were no other differences between the sexes within each environment or between environments within each sex (all P > 0.05) (Table 1). Additive genetic variation for $\beta$ also showed a difference for females in the two environments, but in the opposite direction compared to lifespan $(\mathrm{P}=0.046)$. No other differences in amount of additive genetic variation between the sexes or environments were found for $\beta$ (all $\mathrm{P}>0.05$ ) (Table 1 ). We also calculated the degree of sexual dimorphism for each hemiclone in each replicate (50 hemiclones $\mathrm{x} 4$ replicates), which allowed us to test for additive genetic variation for sexual dimorphism. Additive genetic variation for sexual dimorphism was highly significant for lifespan (Figure 1E,F, ANOVA: SSE $\left.\mathrm{F}_{49,150}=3.44, \mathrm{P}<0.001, \mathrm{MSE} \mathrm{F}_{49,150}=2.36, \mathrm{P}<0.001\right)$ and aging in the SSE (Figure $1 \mathrm{G}$ ANOVA $\mathrm{F}_{49,150}=1.86, \mathrm{P}=0.002$ ), while less so in the MSE (Figure $1 \mathrm{H}$ ANOVA MSE F $49,150=1.41, \mathrm{P}=0.060)$.

\section{Additive genetic correlations and decomposition of additive genetic variation}

The additive genetic correlations for lifespan between environments for each sex $\left(r_{\text {females }}=0.44\right.$, $\left.r_{\text {males }}=0.68\right)$ and those between the sexes in each environment $\left(r_{\mathrm{MSE}}=0.44, r_{\mathrm{SSM}}=0.29\right)$ were relatively low, given that a departure from a correlation of one reflects that genotypes express genetic mortal disease to different degrees in the sexes and environments. All but the correlation between the sexes in the SSE were significantly different from 0 (Figure 2A,B, Table 2). Of the corresponding correlations for $\beta$ ( $r_{\text {females }}=-0.20, r_{\text {males }}=0.66, r_{\mathrm{MSE}}=0.13, r_{\mathrm{SSM}}=-0.13$ ), only the one between males in the two social environments differed significantly from 0 (Table 2). The low additive genetic correlations between sexes and environments, for lifespan as well as $\beta$, was explained by strong hemiclone $\times$ social environment or hemiclone $\times$ sex interactions 
(Figure 2C), as opposed to by estimates sampled with poor precision. These interactions were all significant and more than $75 \%$ of the total genetic variation in both environments for both lifespan and $\beta$ would be free to respond to direction selection in one sex even if it was under stabilizing selection in the other sex (Figure 3A).

\section{Heritability of lifespan}

We used the estimated $V_{A}$ and $V_{P}$ from each sex within each social environment to calculate within sex heritabilities (i.e. father-to-son and mother-to-daughter). The within sex heritabilities were all significantly different from 0 and ranged from 0.25 to 0.40 in the two social environments, but they were not significantly different from one another (all $\mathrm{P}>0.05$ : Figure 3B). The cross-sex heritabilities ranged from 0.10 to 0.12 and were significantly different from 0 in the MSE (both $\mathrm{P}=0.01$ ), but not in the SSE (both $\mathrm{P}=0.083$ ) (Figure 3B). Coheritabilies as estimated following Falconer and Mackay (1996) gave very similar values (coheritability \pm SE in MSE: $0.119 \pm 0.074$, SSE: $0.111 \pm 0.051$ ). Cross-sex heritabilities were significantly lower than the within-sex heritabilites in 6 out of 8 of the interesting comparisons $(\mathrm{M}=$ mother, $\mathrm{F}=$ Father, $\mathrm{D}=$ daughter $\mathrm{S}=$ son; MD-MS and FS-FD in both social environments and MD-FD in SSE and FS-MS in MSE all $\mathrm{P}<0.001$; FS-MS in SSE $\mathrm{P}=0.068$ and MD-FD in MSE $\mathrm{P}=0.12$ ). As all experimental flies had inherited their hemiclone genomes from their father all measures of heritability were deprived of confounding maternal effects (i.e. maternal effects could not have inflated mother-offspring heritabilities).

\section{Discussion}

Research on the genetics of lifespan has given contradictory results concerning the sexspecificity of genes coding for variation in lifespan, where studies assaying flies under conditions close to their natural conditions have found less evidence for sex-specificity 
(Curtsinger 2002; Curtsinger et al. 1998; Forbes et al. 2004; Leips and Mackay 2002; Nuzhdin et al. 2005; Nuzhdin et al. 1997; Reiwitch and Nuzhdin 2002; Wang et al. 2004; Vieira et al. 2000; Wilson et al. 2006). Our study supports that sex-specific effects are stronger when flies are prevented from reproducing, as the degree of sexual dimorphism and the relative amount of sex-specific genetic variation was higher in this environment. However, contrary to previous QTL analyses focusing on major genes, our more holistic study of standing genetic variation clearly demonstrates that sex-specific variation for lifespan and aging not only exists, but that it is the most common form of additive genetic variation across the genome, independent of social environment.

The high proportion of sex-specific additive genetic variation had a large influence on the heritability of lifespan. Heritability is commonly estimated either from offspring and midparental values or separately for males and females (Falconer and Mackay 1996; Lynch and Walsh 1998), while heritabilities between the sexes (father-daughter and mother-son) are rarely considered (but see Bonduriansky and Rowe 2005; Simmons and Ward 1991). For traits hosting considerable amounts of sex-specific variation, heritability between opposite sex family members are predicted to be substantially lower than those between members of the same sex, as the sexes do not share all their additive genetic variation. Our breeding design allowed us to measure the heritability of lifespan between all four parent-offspring combinations (father-son, father-daughter, mother-son and mother-daughter), without any maternal effects inflating the heritability between mothers and offspring. As predicted, heritabilities between same-sex and opposite-sex family members differed extensively, with within sex heritabilities being as much as 2-4 times higher than cross-sex heritabilities. 
Although no previous study, as far as we are aware, has considered sex-specific heritabilities for lifespan a few studies on other insect species have measured the additive intersexual genetic correlation for this trait. The results from these studies vary, but in general support a low additive $r_{\mathrm{MF}}$ for lifespan [seed beetles: population Burkina Faso $\sim 0.4$, population South India 0.8 (Fox et al. 2004a); dung flies: 0.16 (Muhlhauser and Blanckenhorn 2004); crickets: 0.29 (Zajitschek et al. 2007)]. Substantially lower cross-sex than within-sex heritabilities for lifespan may therefore be a commonly occurring phenomenon.

Traditional heritability estimates might be biased if there is substantial sex-specific genetic variation. When the heritability is estimated by taking both sexes into account (for example by regressing offspring on the mid-parental value), the amount of additive genetic variation might be underestimated, since phenotypes of opposite-sex parents contribute to the predictor, while they are less informative about the relevant breeding value as compared to same-sex parents. From the perspective of the sex-specific breeding value they add noise to the predictor, which causes the regression slope to be shallower than it would be if both parent's phenotypes were equally informative about the sex-specific breeding value. Only when the heritability is calculated for each sex-separately, sex-specific additive genetic variation is taken fully into account. Estimates of heritability specifically for each sex will therefore, in general, provide higher and unbiased estimates of the sex-specific heritability, and should hence be better predictors of short-term evolutionary change for traits where sex-specific additive genetic variation is common. The downside of this approach is that there are often less data on close relatives of the same sex available, so that sex-specific heritabilities are estimates with lower precision. Our hemiclone analysis circumvents this problem. 
We used a non-standard estimate, the cross-sex heritability, for describing sex-dependent additive genetic variation. As defined here the cross-sex heritability is

$$
h^{2}{ }_{M F}=h_{M}^{2} \cdot r_{M F}=\frac{V_{A_{M}}}{V_{P_{M}}} \cdot \frac{\operatorname{COV}_{A_{M F}}}{\sqrt{V_{A_{M}}} \sqrt{V_{A_{F}}}}=\frac{\operatorname{COV}_{A_{M F}}}{V_{P_{M}}} \cdot \frac{\sqrt{V_{A_{M}}}}{\sqrt{V_{A_{F}}}}
$$

and ranges between -1 and +1 (or 0 and +1 if absolute values of covariances are used). This metric can be asymmetrical (i.e. $h^{2}{ }_{M F} \neq h_{F M}^{2}$ ) if the additive genetic variances differ between the sexes. The cross-sex heritability can be thought of in two ways. First, it represents that proportion of the phenotypic variance in the parental sex (e.g. $\left.h_{M}^{2}=V_{A_{M}} / V_{P_{M}}\right)$ scaled by the proportion of the genetic variance that is shared between the sexes $\left(r_{M F}=\operatorname{COV}_{A_{M F}} /\left(V_{A_{M}}{ }^{1 / 2}\right.\right.$. $\left.V_{A_{M}}{ }^{1 / 2}\right)$. The product gives the proportion of the phenotypic variance in the parental sex that is informative about the breeding values in the offspring sex. Second, it can be thought of as the regression slope of offspring breeding values on phenotypes of opposite sex relatives $\operatorname{COV}_{A_{M F}} / V_{P_{M}}$ scaled by the potentially unequal additive genetic variances in the two sexes $V_{A_{M}}{ }^{1 / 2} / V_{A_{M}}{ }^{1 / 2}$. The scaling is necessary if we aim to not only predict breeding values of offspring based on parental phenotypes (which would be the slope $\operatorname{COV}_{A_{M F}} / V_{P_{M}}$ ), but also standardize the prediction to the range \pm 1 and thereby make it comparable to the within-sex heritability.

The metric offers an offspring perspective on the information content in parental phenotypes about the genetic predisposition of individual offspring. The cross-sex heritability therefore represents the ratio of the shared genetic variance to the phenotypic variance in the parental sex. This is useful as a benchmark that can be compared to the within-sex heritability, but does not replace population-wide quantitative genetic parameters such as the genetic correlation or the coheritability $\left(\left(h_{F}^{2} \cdot h_{M}^{2}\right)^{1 / 2} \cdot r_{M F}\right.$, (Falconer and Mackay 1996). While the coheritability is 
useful for predicting the correlated response to selection (Falconer and Mackay 1996), the cross-sex heritability is useful as a decomposition of the phenotypic variance.

The rate of aging parameter, $\beta$, was also sexually dimorphic and had significant amounts of additive genetic variation, of which most was sex-specific. Differences in the rate of aging between males and females have previously been found e.g. Fox et al (2004a) and there are also several studies that have shown that this trait is genetically variable (e.g. Fox et al. 2006; Hughes and Charlesworth 1994; Maklakov et al. 2009; Maklakov et al. 2006; Wilson et al. 2007). It has, however, to our knowledge never been reported that the genetic architecture for this trait is vastly different between the sexes. It is not possible to estimate the heritability of actuarial aging in a meaningful way, since it is a rate parameter that cannot be estimated from single individuals, which permits estimates of phenotypic variation at the individual level (Promislow et al. 1996). Our results do, however, indicate that also aging shows higher resemblance between parents and offspring of the same compared to the opposite sex.

Why is then sex-specific additive genetic variation for lifespan and aging so abundant? The most plausible explanation is that the genetic architectures of these traits have become different in the sexes through sex-specific selection, in response to the different routes by which males and females optimize fitness (Bonduriansky et al. 2008). Another, partly dependent possibility, is that selection efficiently removes additive genetic variation that has similar deleterious effects on lifespan and aging in the two sexes, while it less efficiently removes genetic variation that is only selected upon in one sex, or in opposite directions in the two sexes. Mutations with sexspecific effects are likely to have smaller negative selection coefficients when averaged across the sexes, and it thus takes longer for such mutations to be removed or fixed, making them relatively more common at any given time. 
Sex-specific additive genetic variation is synonymous with additive genetic variation for sexual dimorphism. Our results thus show that the degree of sexual dimorphism for lifespan and aging readily can evolve in this population. It has previously been shown in seed beetles that lifespan can evolve rapidly and, at least partly, independently in males and females (Berg and Maklakov 2012; Fox et al. 2011; Maklakov et al. 2009; Maklakov et al. 2007). We note that lifespan and aging, as all life history traits, per se are under directional selection in both sexes, but that males and females can be selected to allocate resources differently into traits connected to lifespan and aging, which may result in sexual differences in these traits.

Male and female experimental hemiclones were generated using different mothers (either normal Dahomey females, or females carrying the same Dahomey autosomal background but with a Y and an attached-X chromosome instead of two normal $\mathrm{X}$ chromosomes). If these mothers provisioned their eggs differently, maternal-by-offspring genotype interactions could potentially have reduced the genetic covariance between the sexes for lifespan and aging. To what extent maternal-by-offspring genotype interactions exist is not easy to evaluate, as the literature on this topic is very sparse. The few studies that do report on maternal-by-offspring genotype interactions are further not very relevant to life-history traits in Drosophila (but see Byers et al. 1997; Cowley et al. 1989; Evans and Kermicle 2001). The fact that maternal effects in general exert their effects during early development, and not in later adult life (Heath et al. 1999), does however suggest that maternal-by-offspring genotype interactions, if they exists at all, should be small for the traits studied here.

In the same-sex environment there is an additional potential confounding factor that could have inflated the estimated sex- and environmental-specific additive genetic variance. In this 
unnatural environment females lived substantially longer than males and allelic variants with very late acting effects could hence primarily have been expressed in females. We acknowledge this possibility but suggest that the low genetic correlation between females in the two environments instead predominately is a result of that mating profoundly changes the female gene expression profile (e.g. Innocenti and Morrow 2009; McGraw et al. 2004). Lifespan is thus likely to become influenced by partly different sets of genes in mated and virgin females. There is also evidence for substantial genetic variation in female ability to resist (in terms of reduced fitness) male courtship and mating (Linder and Rice 2005). While this variation should be expressed in the mixed-sex environment, it should not have affected variation in lifespan in the same-sex environment. The potential confound of late acting genetic variation in females does in any instant not concern the main result of this study, that sex-specific genetic variation for lifespan and aging is substantial in the environment the flies are adapted to, as the degree of sexual dimorphism was small in the mating environment.

Our finding, that lifespan and rate of aging host large amounts of sex-specific genetic variation, has implications for our view of genetic variants causing heritable mortal disease. Given that the sexes have so different genetic architecture for these traits, most genetic variants affecting lifespan and aging must have different effects on disease in males and females. While this is true in D. melanogaster it does not seem farfetched to assume that this is also the case for humans, as humans show a similar degree of sexual dimorphism (Teriokhin et al. 2004) and heritability for lifespan (Cournil et al. 2000; Gogele et al. 2011; Herskind et al. 1996; Kerber et al. 2001; Ljungquist et al. 1998; McArdle et al. 2006; Mitchell et al. 2001; Pettay et al. 2005). There is also a growing awareness that many humans diseases may have a sex-specific component (Ober et al. 2008) and together this calls for more detailed investigations into the sex-specificity of genetic variants underlying mortal disease in humans. 


\section{Acknowledgements}

We thank Henrik Lysell for technical assistance and Rebecca Dean, Damian Dowling, Leif

Engqvist, Arild Husby, Alexei Maklakov, Erik Postma, Felix Zajitschek, as well as Kimberley A. Hughes and three anonymous reviewers for comments on an earlier version of the paper. The work was supported by the Swedish Foundation for Strategic Research and the Swedish Research Council to UF. HS was supported by an Emmy Noether fellowship of the German Research Foundation (DFG) (SCHI 1188/1-1). 


\section{References}

Abbott, J. K., and E. H. Morrow. 2011. Obtaining snapshots of genetic variation using hemiclonal analysis. Trends in Ecology \& Evolution 26:359-368.

Ashman, T. L., and C. J. Majetic. 2006. Genetic constraints on floral evolution: a review and evaluation of patterns. Heredity 96:343-352.

Berg, E. C., and A. A. Maklakov. 2012. Sexes suffer from suboptimal lifespan because of genetic conflict in a seed beetle. Proceedings of the Royal Society B-Biological Sciences 279:4296-4302.

Bonduriansky, R. 2007. The genetic archetecture of sexual dimorphism: the potential roles of genomic imprinting and condition dependence, Pages 176-184 in D. J. Fairbairn, W. U. Blanckenhorn, and T. Szekely, eds. Sex, size and geneder roles:Evolutionary studies of sexual size dimorphism. Oxford, U.K., Oxford University Press.

Bonduriansky, R., and S. F. Chenoweth. 2009. Intralocus sexual conflict. Trends in Ecology \& Evolution 24:280-288.

Bonduriansky, R., A. Maklakov, F. Zajitschek, and R. Brooks. 2008. Sexual selection, sexual conflict and the evolution of ageing and life span. Functional Ecology 22:443-453.

Bonduriansky, R., and L. Rowe. 2005. Intralocus sexual conflict and the genetic architecture of sexually dimorphic traits in Prochyliza xanthostoma (Diptera: Piophilidae). Evolution 59:1965-1975.

Byers, D. L., G. A. J. Platenkamp, and R. G. Shaw. 1997. Variation in seed characters in Nemophila menziesii: Evidence of a genetic basis for maternal effect. Evolution 51:1445-1456.

Clutton-Brock, T. H., and K. Isvaran. 2007. Sex differences in ageing in natural populations of vertebrates. Proceedings of the Royal Society B-Biological Sciences 274:3097-3104.

Cournil, A., J. M. Legay, and F. Schachter. 2000. Evidence of sex-linked effects on the inheritance of human longevity: a population-based study in the Valserine valley (French Jura), 18-20th centuries. Proceedings of the Royal Society of London Series B-Biological Sciences 267:10211025.

Cowley, D. E., and W. R. Atchley. 1988. Quantitative genetics of Drosophila melanogaster 2. Heritabilities and genetic correlations between sexes for head and thorax traits. Genetics 119:421-433.

Cowley, D. E., W. R. Atchley, and J. J. Rutledge. 1986. Quantitative genetics of Drosophila melanogaster 1. Sexual dimorphism in genetic parameters for wing traits. Genetics 114:549-566.

Cowley, D. E., D. Pomp, W. R. Atchley, E. J. Eisen, and D. Hawkinsbrown. 1989. The impact of maternal uterine genotype on postnatal-growth and adult body size in mice. Genetics 122:193-203.

Curtsinger, J. W. 2002. Sex specificity, life-span QTLs, and statistical power. Journals of Gerontology Series a-Biological Sciences and Medical Sciences 57:B409-B414.

Curtsinger, J. W., H. H. Fukui, A. S. Resler, K. Kelly, and A. A. Khazaeli. 1998. Genetic analysis of extended life span in Drosophila melanogaster - I. RAPD screen for genetic divergence between selected and control lines. Genetica 104:21-32.

Delph, L. F., A. M. Arntz, C. Scotti-Saintagne, and I. Scotti. 2010. The genomic architecture of sexual dimorphism in the dioecious plant Silene latifolia. Evolution 64:2873-2886.

Delph, L. F., F. M. Frey, J. C. Steven, and J. L. Gehring. 2004. Investigating the independent evolution of the size of floral organs via G-matrix estimation and artificial selection. Evolution \& Development 6:438-448.

Evans, M. M. S., and J. L. Kermicle. 2001. Interaction between maternal effect and zygotic effect mutations during maize seed development. Genetics 159:303-315.

Fairbairn, D. J., W. U. Blanckenhorn, and T. Székely. 2007, Sex, size, and gender roles: evolutionary studies of sexual size dimorphism: Oxford biology. Oxford; New York, Oxford University Press.

Fairbairn, D. J., and D. A. Roff. 2006. The quantitative genetics of sexual dimorphism: assessing the importance of sex-linkage. Heredity 97:319-328.

Falconer, D. S., and T. F. C. Mackay. 1996, Introduction to quantitative genetics. Essex, UK, Longman Group Ltd. 
Forbes, S. N., R. K. Valenzuela, P. Keim, and P. M. Service. 2004. Quantitative trait loci affecting life span in replicated popidations of Drosophila melanogaster. I. Composite interval mapping. Genetics 168:301-311.

Fox, C. W., M. L. Bush, D. A. Roff, and W. G. Wallin. 2004a. Evolutionary genetics of lifespan and mortality rates in two populations of the seed beetle, Callosobruchus maculatus. Heredity 92:170-181.

Fox, C. W., M. E. Czesak, and W. G. Wallin. 2004b. Complex genetic architecture of population differences in adult lifespan of a beetle: nonadditive inheritance, gender differences, body size and a large maternal effect. Journal of Evolutionary Biology 17:1007-1017.

Fox, C. W., K. L. Scheibly, W. G. Wallin, L. J. Hitchcock, R. C. Stillwell, and B. P. Smith. 2006. The genetic architecture of life span and mortality rates: Gender and species differences in inbreeding load of two seed-feeding beetles. Genetics 174:763-773.

Fox, C. W., J. D. Wagner, S. Cline, F. A. Thomas, and F. J. Messina. 2011. Rapid evolution of lifespan in a novel environment: Sex-specific responses and underlying genetic architecture. Evolutionary Biology 38:182-196.

Friberg, U. 2005. Genetic variation in male and female reproductive characters associated with sexual conflict in Drosophila melanogaster. Behavior Genetics 35:455-462.

Friberg, U., T. A. Lew, P. G. Byrne, and W. R. Rice. 2005. Assessing the potential for an ongoing arms race within and between the sexes: Selection and heritable variation. Evolution 59:1540-1551.

Gogele, M., C. Pattaro, C. Fuchsberger, C. Minelli, P. P. Pramstaller, and M. Wjst. 2011. Heritability analysis of life span in a semi-isolated population followed across four centuries reveals the presence of pleiotropy between life span and reproduction. Journals of Gerontology Series aBiological Sciences and Medical Sciences 66:26-37.

Hadfield, J. D. 2010. MCMC methods for multi-response generalized linear mixed models: The MCMCgImm R package. Journal of Statistical Software 33:1-22.

Hansen, T. F., W. S. Armbruster, M. L. Carlson, and P. E. C. 2003. Evolvability and genetic constraint in Dalechampia blossoms: genetic correlations and conditional evolvability. J Exp Zool B Mol Dev Evol 296:23-39.

Hansen, T. F., C. Pelabon, and D. Houle. 2011. Heritability is not evolvability. Evolutionary Biology 38:258-277.

Hazzard, W. R. 1986. Biological basis of the sex differential in longevity. Journal of the American Geriatrics Society 34:455-471.

Heath, D. D., C. W. Fox, and J. W. Heath. 1999. Maternal effects on offspring size: Variation through early development of chinook salmon. Evolution 53:1605-1611.

Herskind, A. M., M. McGue, N. V. Holm, T. I. Sorensen, B. Harvald, and J. W. Vaupel. 1996. The heritability of human longevity: a population-based study of 2872 Danish twin pairs born $1870-$ 1900. Hum Genet 97:319-323.

Hill, W. G., M. E. Goddard, and P. M. Visscher. 2008. Data and theory point to mainly additive genetic variance for complex traits. PLoS Genet 4:e1000008.

Hughes, K. A., and B. Charlesworth. 1994. A genetic analysis of senescence in Drosophila. Nature 367:64-66.

Innocenti, P., and E. H. Morrow. 2009. Immunogenic males: a genome-wide analysis of reproduction and the cost of mating in Drosophila melanogaster females. Journal of Evolutionary Biology 22:964-973.

Kerber, R. A., E. O'Brien, K. R. Smith, and R. M. Cawthon. 2001. Familial excess longevity in Utah genealogies. Journals of Gerontology Series a-Biological Sciences and Medical Sciences 56:B130-B139.

Lande, R. 1980. Sexual dimorphism, sexual selection, and adaptation in polygenic characters. Evolution 34:292-305.

-. 1987. Genetic correlations between the sexes in the evolution of sexual dimorphism and mating preferences, Pages xi, 308 p. in J. W. Bradbury, and M. B. Anderson, eds. Sexual selection: 
testing the alternatives: report of the Dahlem Workshop on Sexual Selection: Testing the Alternatives. Chichester; New York, Wiley.

Leinonen, T., J. M. Cano, and J. Merila. 2011. Genetic basis of sexual dimorphism in the threespine stickleback Gasterosteus aculeatus. Heredity 106:218-227.

Leips, J., and T. F. C. Mackay. 2002. The complex genetic architecture of Drosophila life span. Experimental Aging Research 28:361-390.

Liker, A., and T. Szekely. 2005. Mortality costs of sexual selection and parental care in natural populations of birds. Evolution 59:890-897.

Linnen, C., M. Tatar, and D. Promislow. 2001. Cultural artifacts: a comparison of senescence in natural, laboratory-adapted and artificially selected lines of Drosophila melanogaster. Evolutionary Ecology Research 3:877-888.

Ljungquist, B., S. Berg, J. Lanke, G. E. McClearn, and N. L. Pedersen. 1998. The effect of genetic factors for longevity: A comparison of identical and fraternal twins in the Swedish twin registry. Journals of Gerontology Series a-Biological Sciences and Medical Sciences 53:M441-M446.

Lovich, J. E., and J. W. Gibbons. 1992. A review of techniques for quantifying sexual size dimorphism. Growth Development and Aging 56:269-281.

Lynch, M., and B. Walsh. 1998, Genetics and analysis of quantitative traits. Sunderland, Mass., Sinauer. Maklakov, A. A. 2008. Sex difference in life span affected by female birth rate in modern humans. Evolution and Human Behavior 29:444-449.

Maklakov, A. A., R. Bonduriansky, and R. C. Brooks. 2009. Sex differences, sexual selection, and ageing: An experimental evolution approach. Evolution 63:2491-2503.

Maklakov, A. A., U. Friberg, D. K. Dowling, and G. Arnqvist. 2006. Within-population variation in cytoplasmic genes affects female life span and aging in Drosophila melanogaster. Evolution Int J Org Evolution 60:2081-2086.

Maklakov, A. A., C. Fricke, and G. Arnqvist. 2007. Sexual selection affects lifespan and aging in the seed beetle. Aging Cell 6:739-744.

McArdle, P. F., T. I. Pollin, J. R. O'Connell, J. D. Sorkin, R. Agarwala, A. A. Schaffer, E. A. Streeten et al. 2006. Does having children extend life span? A genealogical study of parity and longevity in the Amish. Journals of Gerontology Series a-Biological Sciences and Medical Sciences 61:190195.

McDaniel, S. F. 2005. Genetic correlations do not constrain the evolution of sexual dimorphism in the moss Ceratodon purpureus. Evolution 59:2353-2361.

McGraw, L. A., G. Gibson, A. G. Clark, and M. F. Wolfner. 2004. Genes regulated by mating, sperm, or seminal proteins in mated female Drosophila melanogaster. Current Biology 14:1509-1514.

Meagher, T. R. 1992. The quantitative genetics of sexual dimorphism in Silene latifolia (Caryophyllaceae) .1. Genetic variation. Evolution 46:445-457.

Mitchell, B. D., W. C. Hsueh, T. M. King, T. I. Pollin, J. Sorkin, R. Agarwala, A. A. Schaffer et al. 2001. Heritability of life span in the old order Amish. American Journal of Medical Genetics 102:346352.

Muhlhauser, C., and W. U. Blanckenhorn. 2004. The quantitative genetics of sexual selection in the dung fly sepsis cynipsea. Behaviour 141:327-341.

Nuzhdin, S. V., A. A. Khazaeli, and J. W. Curtsinger. 2005. Survival analysis of life span quantitative trait loci in Drosophila melanogaster. Genetics 170:719-731.

Nuzhdin, S. V., E. G. Pasyukova, C. L. Dilda, Z. B. Zeng, and T. F. C. Mackay. 1997. Sex-specific quantitative trait loci affecting longevity in Drosophila melanogaster. Proceedings of the National Academy of Sciences of the United States of America 94:9734-9739.

Ober, C., D. A. Loisel, and Y. Gilad. 2008. Sex-specific genetic architecture of human disease. Nature Reviews Genetics 9:911-922.

Partridge, L., and D. Gems. 2006. Beyond the evolutionary theory of ageing, from functional genomics to evo-gero. Trends in Ecology \& Evolution 21:334-340. 
Pettay, J. E., L. E. B. Kruuk, J. Jokela, and V. Lummaa. 2005. Heritability and genetic constraints of lifehistory trait evolution in preindustrial humans. Proceedings of the National Academy of Sciences of the United States of America 102:2838-2843.

Pletcher, S. D. 1999. Model fitting and hypothesis testing for age-specific mortality data. Journal of Evolutionary Biology 12:430-439.

Poissant, J., A. J. Wilson, and D. W. Coltman. 2010. Sex-specific genetic variance and the evolution of sexual dimorphism: A systematic review of cross-sex genetic correlations. Evolution 64:97-107.

Promislow, D. E. L., M. Tatar, A. A. Khazaeli, and J. W. Curtsinger. 1996. Age-specific patterns of genetic variance in Drosophila melanogaster .1. Mortality. Genetics 143:839-848.

Reeve, J. P., and D. J. Fairbairn. 2001. Predicting the evolution of sexual size dimorphism. Journal of Evolutionary Biology 14:244-254.

Reiwitch, S. G., and S. V. Nuzhdin. 2002. Quantitative trait loci for lifespan of mated Drosophila melanogaster affect both sexes. Genetical Research 80:225-230.

Rice, W. R., J. E. Linder, U. Friberg, T. A. Lew, E. H. Morrow, and A. D. Stewart. 2005. Inter-locus antagonistic coevolution as an engine of speciation: Assessment with hemiclonal analysis. Proceedings of the National Academy of Sciences of the United States of America 102:65276534.

Simmons, L. W., and P. I. Ward. 1991. The heritability of sexually dimorphic traits in the yellow dung fly Scathophaga stercoraria (L). Journal of Evolutionary Biology 4:593-601.

Teriokhin, A. T., E. V. Budilova, F. Thomas, and J. F. Guegan. 2004. Worldwide variation in life-span sexual dimorphism and sex-specific environmental mortality rates. Human Biology 76:623641.

Trivers, R. 1972. Parental investment and sexual selection., Pages 136-179 in B. Campbell, ed. Sexual selection and the descent of man 1871-1971. Chicago, Aldine.

Wang, M. H., O. Lazebny, L. G. Harshman, and S. V. Nuzhdin. 2004. Environment-dependent survival of Drosophila melanogaster: a quantitative genetic analysis. Aging Cell 3:133-140.

Vieira, C., E. G. Pasyukova, Z. B. Zeng, J. B. Hackett, R. F. Lyman, and T. F. C. Mackay. 2000. Genotypeenvironment interaction for quantitative trait loci affecting life span in Drosophila melanogaster. Genetics 154:213-227.

Wilson, A. J., D. H. Nussey, J. M. Pemberton, J. G. Pilkington, A. Morris, F. Pelletier, T. H. Clutton-Brock et al. 2007. Evidence for a genetic basis of aging in two wild vertebrate populations. Current Biology 17:2136-2142.

Wilson, R. H., T. J. Morgan, and T. F. C. Mackay. 2006. High-resolution mapping of quantitative trait loci affecting increased life span in Drosophila melanogaster. Genetics 173:1455-1463.

Zajitschek, F., J. Hunt, S. R. K. Zajitschek, M. D. Jennions, and R. Brooks. 2007. No intra-locus sexual conflict over reproductive fitness or ageing in field crickets. Plos One 2. 
Table 1: Summary statistics for lifespan and the rate of aging parameter $\beta$.

\begin{tabular}{|c|c|c|c|c|c|c|}
\hline Category & mean & $V_{P}$ & $V_{A}$ & $C V_{\mathrm{P}}$ & $C V_{\mathrm{A}}$ & $V_{\text {Vial }}$ \\
\hline q SSE & $58.93 \pm 0.78^{\star \star \star}$ & $111.87 \pm 7.17^{\star \star \star \star}$ & $45.48 \pm 12.79^{\star \star \star \star}$ & 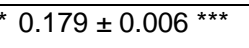 & $0.113 \pm 0.016$ *** & $29.45 \pm 3.57^{\star \star \star}$ \\
\hline$\uparrow$ MSE & $44.69 \pm 0.50 * \star \star$ & $67.46 \pm 2.93$ *** & $17.08 \pm 4.76^{* \star \star}$ & * $0.184 \pm 0.004$ *** & $0.092 \pm 0.013 * * *$ & $16.16 \pm 1.90$ *** \\
\hline SSE & $43.51 \pm 0.56$ *** & $102.65 \pm 3.47^{\star \star \star *}$ & $27.56 \pm 6.33^{* \star \star}$ & 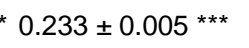 & $0.120 \pm 0.014$ *** & $4.13 \pm 0.63$ *** \\
\hline MSE & $40.14 \pm 0.50$ *** & $66.97 \pm 2.61$ *** & $21.51 \pm 4.94$ *** & * $0.204 \pm 0.005$ *** & $0.115 \pm 0.013 * * *$ & $3.45 \pm 0.49 * * *$ \\
\hline$q$ SSE - $q$ MSE & $14.24 \pm 0.83$ *** & $44.41 \pm 7.61$ *** & $28.41 \pm 13.35$ ** & $-0.004 \pm 0.007$ & $0.022 \pm 0.020$ & \\
\hline SSE - $\lambda$ MSE & $3.35 \pm 0.53$ *** & $35.68 \pm 3.39$ *** & $6.05 \pm 6.04$ & $0.029 \pm 0.005$ *** & $0.005 \pm 0.014$ & \\
\hline$q$ SSE - $\precsim$ SSE & $15.43 \pm 0.88$ *** & $9.22 \pm 7.59$ & $17.93 \pm 13.51$ & $-0.053 \pm 0.007 * \star \star$ & $-0.007 \pm 0.020$ & \\
\hline$\uparrow$ MSE - $\frown$ MSE & $4.53 \pm 0.62$ *** & $0.49 \pm 3.71$ & $-4.43 \pm 6.43$ & $-0.020 \pm 0.006 * \star \star$ & $-0.023 \pm 0.017$ & \\
\hline $\begin{array}{l}\text { ( } \text { SSE - } O \text { SSE) - } \\
\text { ( } Q \text { MSE - } \bigcirc \text { MSE) }\end{array}$ & $10.87 \pm 0.92$ *** & $8.73 \pm 8.11$ & $21.36 \pm 15.41$ & $-0.030 \pm 0.010 * * *$ & $0.020 \pm 0.020$ & \\
\hline
\end{tabular}

\begin{tabular}{|c|c|c|c|c|c|}
\hline Category & mean & $V_{P}$ & $V_{A}$ & $C V_{\mathrm{P}}$ & $C V_{A}$ \\
\hline q SSE & $0.189 \pm 0.004$ *** & 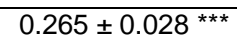 & $0.093 \pm 0.033$ *** & - & - \\
\hline$q$ MSE & $0.250 \pm 0.007^{* \star \star}$ & $0.556 \pm 0.060$ *** & $0.244 \pm 0.083 * \star * *$ & - & - \\
\hline SSE & $0.155 \pm 0.003 * * *$ & $0.092 \pm 0.011$ *** & $0.059 \pm 0.018 * \star \star *$ & - & - \\
\hline MSE & $0.194 \pm 0.005$ *** & $0.288 \pm 0.031$ *** & $0.119 \pm 0.040 * \star *$ & - & - \\
\hline$\uparrow$ SSE - $q$ MSE & $-0.061 \pm 0.008 * * *$ & $-0.291 \pm 0.065 * \star * *$ & $-0.151 \pm 0.089$ * & - & - \\
\hline 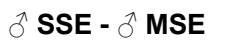 & $-0.039 \pm 0.005 * \star * *$ & $-0.196 \pm 0.032$ *** & $-0.060 \pm 0.042$ & & - \\
\hline$q$ SSE - $\oslash$ SSE & $0.033 \pm 0.005^{* * *}$ & $0.173 \pm 0.030$ *** & $0.034 \pm 0.038$ & - & - \\
\hline$\uparrow$ MSE - $ð$ MSE & $0.056 \pm 0.008^{* * *}$ & $0.269 \pm 0.067$ *** & $0.124 \pm 0.090$ & - & - \\
\hline $\begin{array}{l}(q \text { SSE - SSE) - } \\
(+ \text { MSE - }\end{array}$ & $-0.022 \pm 0.010$ * & $-0.100 \pm 0.070$ & $-0.090 \pm 0.100$ & - & - \\
\hline
\end{tabular}

Note: The first four rows of each section show estimates separately for the sexes and environments, while the following five rows show differences between the estimates. All values are point estimates $\pm \mathrm{SE}$. Statistical significance is flagged $\left({ }^{\circ} \mathrm{P}<0.1, * \mathrm{P}<0.05\right.$, ** $\mathrm{P}<0.01$, *** $\mathrm{P}<0.001) . V_{\mathrm{P}}$ and $V_{\mathrm{A}}$ for $\beta$ are based on among trial variation and are multiplied by 100 for display. $C V_{\mathrm{P}}$ and $C V_{\mathrm{A}}$ are nonsensical for parameters such as the rate of aging that are neither ratio nor log-interval scale (Hansen et al. 2011) 
Table 2: Additive genetic covariances, correlations between sexes and environments for lifespan and the rate of aging parameter $\beta$.

\begin{tabular}{|c|c|c|c|c|}
\hline \multirow[b]{2}{*}{ Category } & \multicolumn{2}{|c|}{ Lifespan (days) } & \multicolumn{2}{|c|}{ Aging $(\beta)$} \\
\hline & Cova & $r_{A}$ & Cova & $r_{A}$ \\
\hline$q$ SSE, $q$ MSE & $12.229 \pm 5.758 *$ & $0.437 \pm 0.160 *$ & $-0.024 \pm 0.036$ & $-0.157 \pm 0.226$ \\
\hline$\precsim$ SSE, $\curvearrowright$ MSE & $16.558 \pm 4.768 * * *$ & $0.675 \pm 0.090 * * *$ & $0.036 \pm 0.020 *$ & $0.426 \pm 0.186 *$ \\
\hline$\uparrow \mathbf{S S E}, \precsim \widehat{~ S S E}$ & $10.409 \pm 6.450^{\circ}$ & $0.293 \pm 0.159^{\circ}$ & $-0.008 \pm 0.017$ & $-0.108 \pm 0.223$ \\
\hline$\uparrow$ MSE, $\overbrace{}^{\lambda}$ MSE & $8.321 \pm 3.643 *$ & $0.429 \pm 0.144 *$ & $0.016 \pm 0.041$ & $0.099 \pm 0.225$ \\
\hline r( $q$ SSE, $\uparrow$ MSE $)-\mathbf{r}(ð$ SSE, $\curvearrowright$ MSE $)$ & - & $-0.238 \pm 0.181$ & - & $-0.583 \pm 0.296^{\circ}$ \\
\hline r( + SSE, $\precsim$ SSE $)-\mathbf{r}(\uparrow$ MSE, $\precsim$ MSE $)$ & - & $-0.136+-0.195$ & - & $-0.207 \pm 0.327$ \\
\hline
\end{tabular}

Note: The first four rows of each section show estimates separately for the sexes and environments, while the following two rows show differences between the estimates. All values are point estimates \pm SE. Statistical significance for tests against zero is flagged $\left({ }^{\circ} \mathrm{P}<0.1\right.$, * $\mathrm{P}<0.05$, ** $\mathrm{P}<0.01$, *** $\mathrm{P}<0.001$ ). The genetic correlations are also different from 1 (see methods). Genetic covariances for $\beta$ are multiplied by 100 for display. 


\section{Figure legends}

Figure 1

Histograms of male (blue) and female (red) hemiclone means for lifespan in the same sex environment (A) and the mixed sex environment (B). Survival curves for each hemiclone (males blue, females red) in the same sex environment (C) and the mixed sex environment (D). Histograms of differences in mean lifespan between male and female hemiclones (i.e. variation in sexual dimorphism) in the same sex environment (E) and the mixed sex environment (F). Histograms of differences in aging $(\beta)$ between the sexes in the same sex environment $(\mathrm{G})$ and the mixed sex environment $(\mathrm{H})$.

\section{Figure 2}

A. Association in lifespan between male and female hemiclones in each social environment. B Association in lifespan between social environments for each sex. Plots A and B are scaled such that the steepness of the regression slopes reflects the strength of the correlation. C. Hemiclones ranked (1-50) after their lifespan when expressed in males or in females in each social environment.

\section{Figure 3}

A. Percent of conditional genetic variation for lifespan and aging $(\beta)$ in males and females in the same sex environment (SSE) and in the mixed-sex environment (MSE). B. Heritability of lifespan between mother and daughter (MD), mother and son (MS), father and son (FS) and father and daughter (FD), in the two social environments. 
Figure 1.
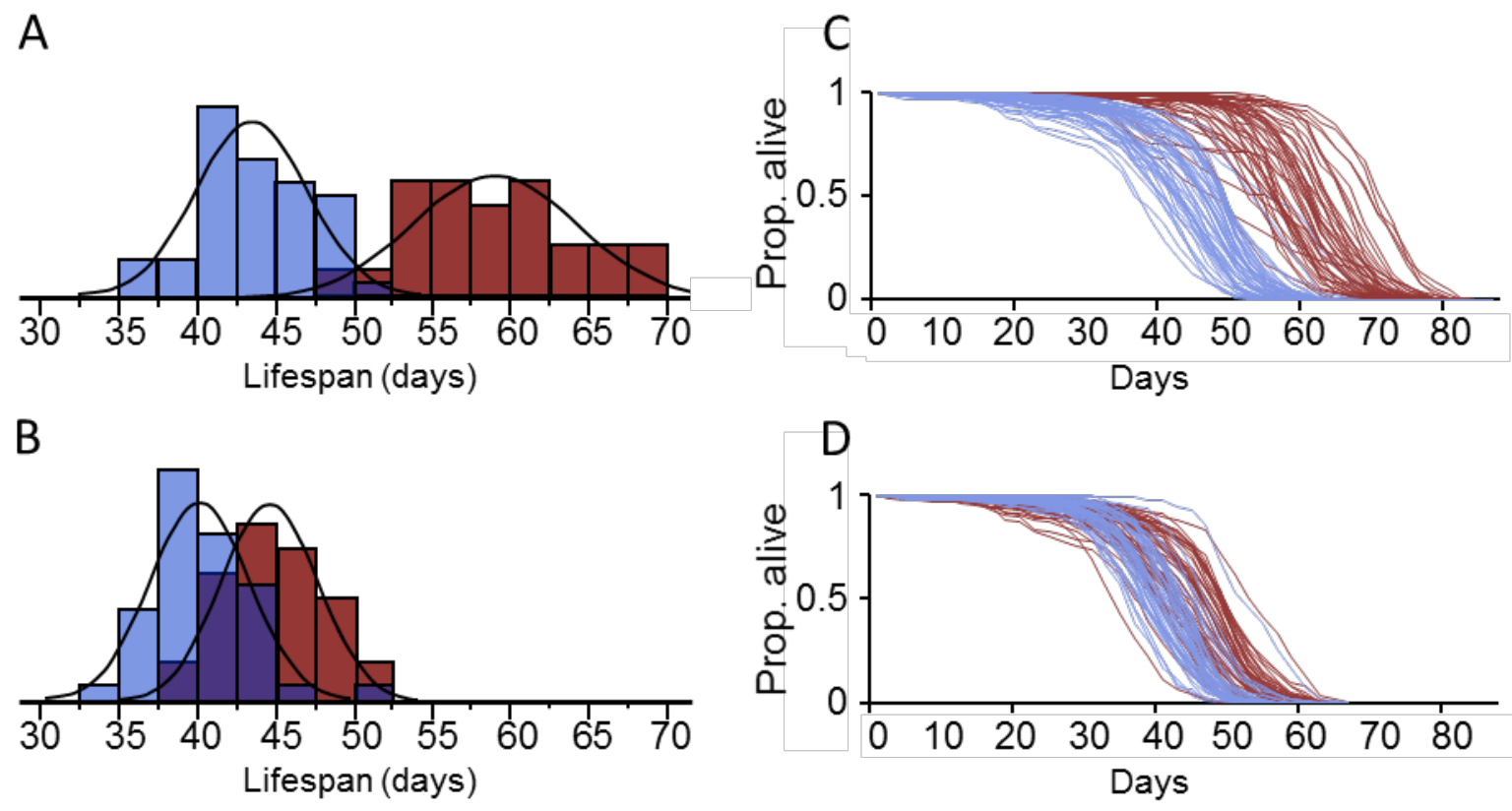

E

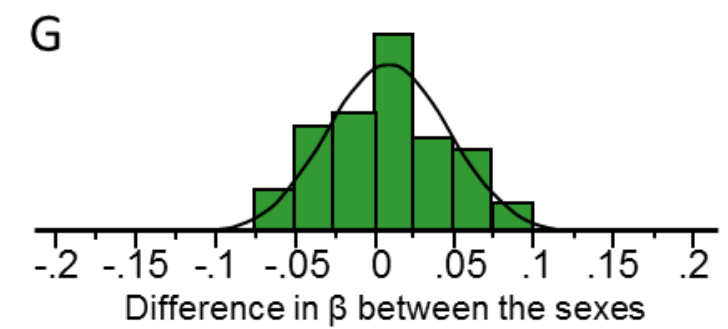

Difference in lifespan between the sexes (days)

$\mathrm{H}$

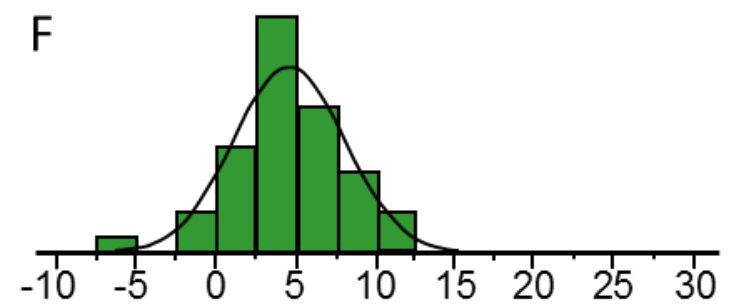

Difference in lifespan between the sexes (days)

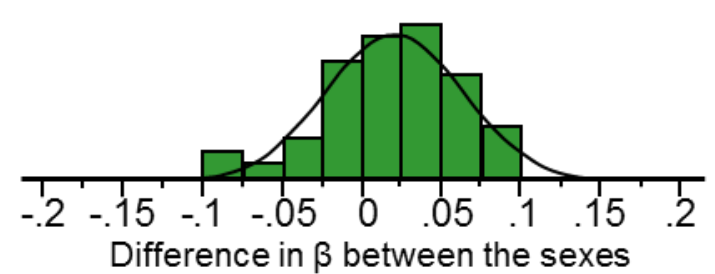


Figure 2a.

Females with males (filled symbols)

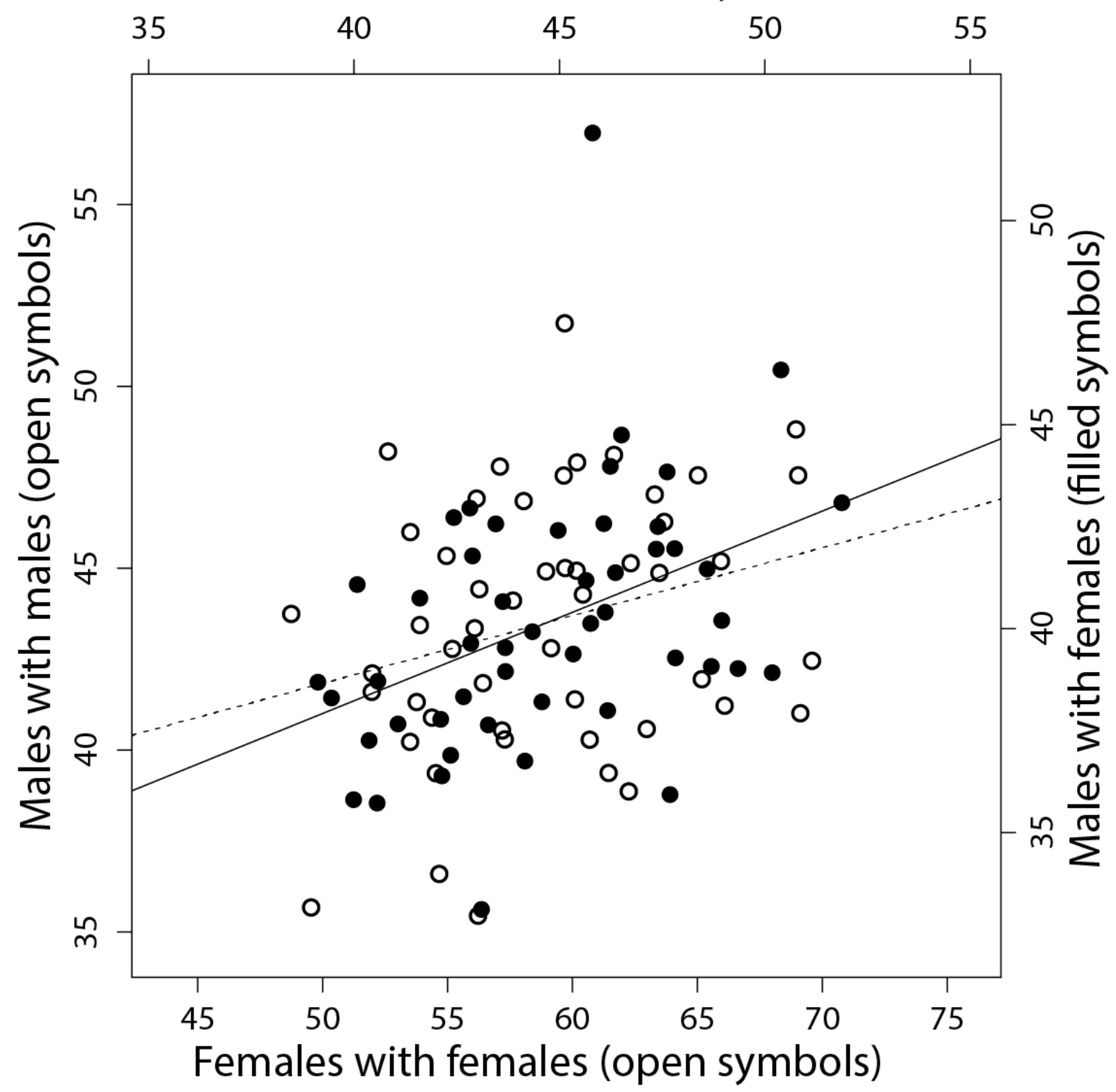


Figure 2b.

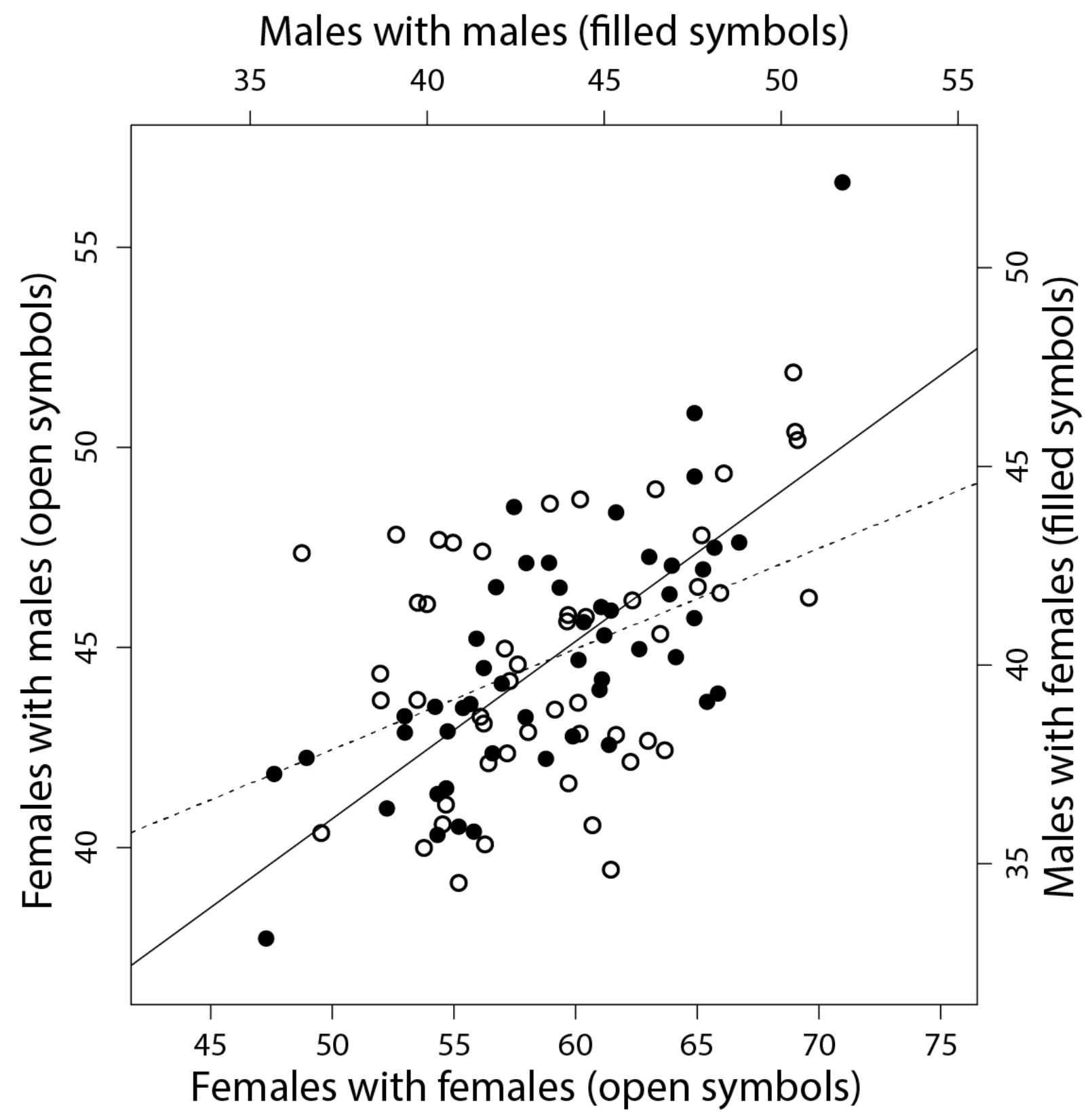


Figure 2c.

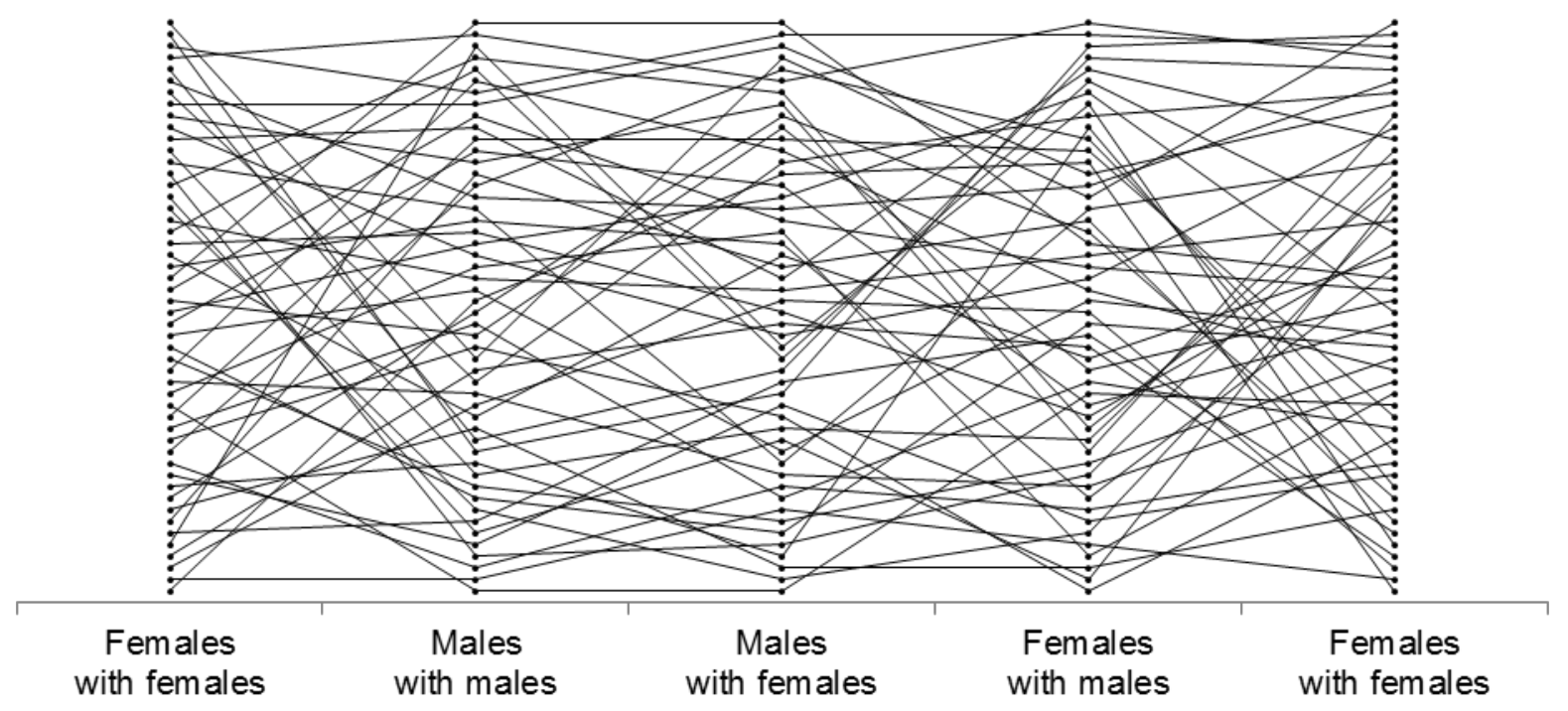


Figure 3.

A

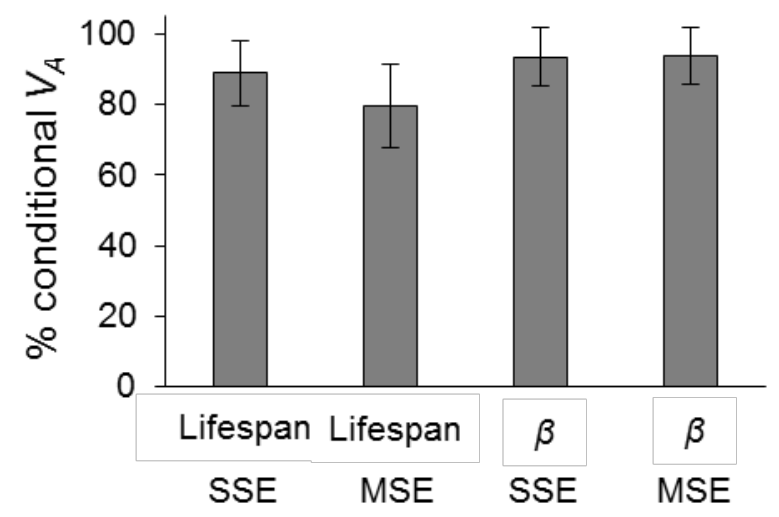

B

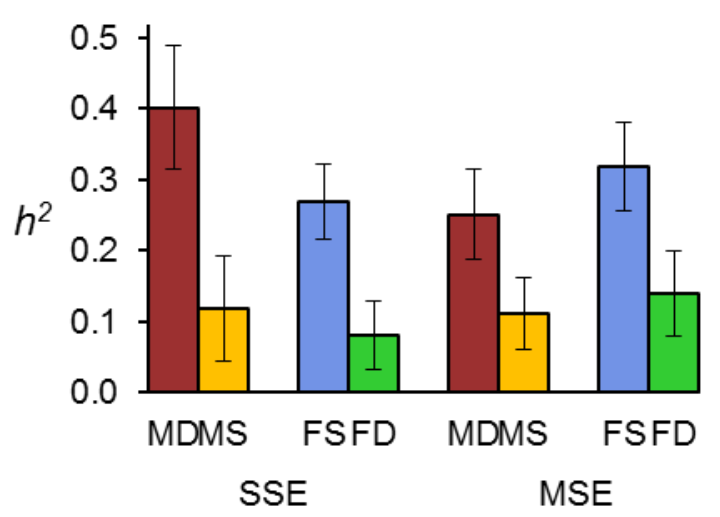

